\title{
Classic congenital adrenal hyperplasia and puberty
}

\author{
Evangelia Charmandari ${ }^{1}$, Charles G D Brook ${ }^{2}$ and Peter C Hindmarsh ${ }^{2}$ \\ ${ }^{1}$ Pediatric and Reproductive Endocrinology Branch, National Institute of Child Health and Human Development, National Institutes of Health, Bethesda, \\ Maryland 20892-1583, USA and ${ }^{2}$ London Centre for Paediatric Endocrinology, University College London, London, UK
}

(Correspondence should be addressed to E Charmandari; Email: charmane@mail.nih.gov)

\begin{abstract}
Congenital adrenal hyperplasia $(\mathrm{CAH})$ is a group of autosomal recessive disorders resulting from deficiency of one of the five enzymes required for synthesis of cortisol in the adrenal cortex. The most common form of the disease is classic 21-hydroxylase deficiency, which is characterized by decreased synthesis of glucocorticoids and often mineralocorticoids, adrenal hyperandrogenism and impaired development and function of the adrenal medulla. The clinical management of classic 21-hydroxylase deficiency is often suboptimal, and patients are at risk of developing in tandem iatrogenic hypercortisolism and/or hyperandogenism. Limitations of current medical therapy include the inability to control hyperandrogenism without employing supraphysiologic doses of glucocorticoid, hyperresponsiveness of the hypertrophied adrenal glands to adrenocorticotropic hormone (ACTH) and difficulty in suppressing ACTH secretion from the anterior pituitary. Puberty imposes increased difficulty in attaining adrenocortical suppression despite optimal substitution therapy and adherence to medical treatment. Alterations in the endocrine milieu at puberty may influence cortisol pharmacokinetics and, consequently, the handling of hydrocortisone used as replacement therapy. Recent studies have demonstrated a significant increase in cortisol clearance at puberty and a shorter half-life of free cortisol in pubertal females compared with males. Furthermore, children with classic $\mathrm{CAH}$ have elevated fasting serum insulin concentrations and insulin resistance. The latter may further enhance adrenal and/or ovarian androgen secretion, decrease the therapeutic efficacy of glucocorticoids and contribute to later development of the metabolic syndrome and its complications.
\end{abstract}

European Journal of Endocrinology 151 U77-U82

\section{Introduction}

Congenital adrenal hyperplasia $(\mathrm{CAH})$ is a group of autosomal recessive disorders resulting from deficiency of one of the five enzymes required for synthesis of cortisol in the adrenal cortex. The most frequent form of the disease is steroid 21-hydroxylase deficiency, which accounts for $90-95 \%$ of all cases of $\mathrm{CAH}(1-4)$. Deletions or mutations of the cytochrome P450 21-hydroxylase gene result in decreased synthesis of glucocorticoids and often mineralocorticoids. The impaired glucocorticoid feedback inhibition at the hypothalamic and anterior pituitary levels leads to increased secretion of corticotropin-releasing hormone $(\mathrm{CRH})$ and adrenocorticotropic hormone (ACTH) respectively, adrenal hyperplasia, and increased production of adrenal androgens and steroid precursors prior to the enzymatic defect (1-5). The clinical spectrum of 21-hydroxylase deficiency is quite broad, ranging from the most severe to mild forms, depending on the degree of 21-hydroxylase activity. Accordingly, three main clinical phenotypes have been described: classic salt-wasting, classic simple virilizing and nonclassic (1,3-5).

In addition to impaired adrenocortical function, classic $\mathrm{CAH}$ is characterized by compromised adrenomedullary function. The latter is due to developmental defects in the formation of the adrenal medulla, which lead to depletion of epinephrine stores and decreased production of metanephrine, the $O$-methylated metabolite of epinephrine (6). Patients with classic CAH have significantly lower plasma and urinary epinephrine, and plasma total and free metanephrine concentrations than normal subjects (6). The degree of adrenomedullary hypofunction in classic $\mathrm{CAH}$ correlates strongly with the degree of adrenocortical impairment and the expected 21-hydroxylase activity based on genotype $(6,7)$.

Current treatment of classic $\mathrm{CAH}$ aims to provide adequate glucocorticoid and, when necessary, mineralocorticoid substitution to prevent adrenal crises and to suppress the excessive secretion of $\mathrm{CRH}$ and ACTH, thereby reducing circulating concentrations of adrenal androgens and steroid precursors. Achieving and maintaining adrenal androgen suppression is far more challenging than preventing adrenal crises, and in a fair number of patients it has proven impossible to control hyperandrogenism without employing supraphysiologic doses of glucocorticoid. Iatrogenic Cushing's syndrome and hyperandrogenism may develop in tandem, representing the main problems encountered in the clinical management of these patients $(1-5)$.

The limitations of standard medical therapy with glucocorticoid and/or mineralocorticoid substitution include: (i) inability to replicate physiologic cortisol 
production with exogenous administration of glucocorticoid; (ii) hyperresponsiveness of the hypertrophied adrenal glands to ACTH and increased androgen production following a small ACTH challenge in the event of escape from pituitary suppression (8); (iii) difficulty in suppressing ACTH secretion from the anterior pituitary due to the decreased sensitivity to glucocorticoid feedback inhibition, as well as the fact that glucocorticoid feedback is only one of the mechanisms governing ACTH secretion (8, 9); (iv) resistance to replacement therapy, given that the increased concentrations of androgens and steroid precursors compete with the exogenously administered glucocorticoids and mineralocorticoids for the same receptors, placing patients with classic $\mathrm{CAH}$ at greater risk of stressinduced salt-losing crises than their healthy or Addisonian counterparts $(8,10,11)$.

In addition to the above, clinical observations suggest that puberty imposes increased difficulty in attaining adrenocortical suppression despite optimal substitution therapy and adherence to medical treatment. Alterations in the endocrine milieu at puberty may influence cortisol pharmacokinetics and, consequently, the handling of hydrocortisone used as replacement therapy.

\section{Alterations in cortisol pharmacokinetics at puberty}

In a prospective, cross-sectional study carried out at the London Centre for Paediatric Endocrinology, London, UK, we determined the pharmacokinetic parameters of total and free cortisol in 40 subjects with classic salt-wasting $\mathrm{CAH}$ (14 prepubertal (M: 5; F: 9), 20 pubertal (M: 7; F: 13) and 6 postpubertal (M: 2; F: 4)) (12). We showed that the clearance (CL) of total and free cortisol was significantly higher in the pubertal than the prepubertal and postpubertal patients. The volume of distribution (V) of total and free cortisol was significantly higher in the pubertal and postpubertal than in prepubertal patients. No difference in the half-life $\left(t_{1 / 2}\right)$ of total or free cortisol was noted between groups. The latter was thought to be due to the concomitant rise in cortisol clearance and volume of distribution, both important determinants of the elimination of a drug from the body and, hence, its halflife $\left(t_{1 / 2}=0.693 * \mathrm{~V} / \mathrm{CL}\right)$. Comparison of the pharmacokinetic parameters of free cortisol between males and females in each separate group of patients (prepubertal, pubertal and postpubertal) revealed a significantly shorter half-life of free cortisol in pubertal females than in pubertal males (12).

The net effect of these changes in cortisol pharmacokinetics, if the administration schedule of hydrocortisone remains unchanged, will be a loss of control of the hypothalamic-pituitary-adrenal (HPA) axis, inadequate suppression of the adrenal cortex and excessive production of adrenal androgens and steroid precursors. Both hypocortisolism and hyperandrogenism may operate as independent factors to amplify the loss of control, while the increased ACTH secretion may further enhance hypocortisolism by increasing the metabolic clearance rate of cortisol (13).

\section{Classic congenital adrenal hyperplasia and puberty}

The primary site of cortisol metabolism in humans is the liver, and a number of cytosolic and microsomal enzymes, including cytochrome P450, 5 $\alpha / 5 \beta$ reductase, $3 \alpha / 3 \beta$-oxidoreductase and 11 $\beta$-hydroxysteroid dehydrogenase, play an important role in the hepatic metabolism of cortisol (14-16). The major routes of hepatic metabolism involve A-ring and sidechain reduction followed in vivo by conjugation with glucuronic acid and sulfate (17). The inactive glucuronide and sulfate metabolites are excreted by the kidneys, whereas only less than $1 \%$ of cortisol is excreted unchanged in the urine. Therefore, the metabolic clearance of cortisol is influenced primarily by factors altering hepatic clearance and to a much lesser extent by factors affecting renal excretion.

The increased cortisol clearance at puberty is most likely due to alterations in the activity of $11 \beta$-hydroxysteroid dehydrogenase (11 $\beta$-HSD). 11 $\beta$-HSD plays a key role in the hepatic metabolism of cortisol by catalyzing the interconversion of active cortisol to its hormonally inactive metabolite, cortisone. Two isoforms of $11 \beta$-HSD have been identified. Type 1 (11ß-HSD1) isoform is a $\mathrm{NADP}(\mathrm{H})$-dependent enzyme highly expressed in the liver, gonads, adipose tissue and central nervous system tissues, where the reaction direction is predominantly $11 \beta$-reduction, converting cortisone to cortisol and potentially increasing active glucocorticoid levels. Type $2(11 \beta-H S D 2)$ isoform is a NAD-dependent dehydrogenase expressed in the mineralocorticoid target tissues, kidney and colon, which catalyzes the conversion of cortisol to cortisone, thus protecting the mineralocorticoid receptor from illicit occupancy by cortisol (18-20).

Both in vivo and in vitro studies have demonstrated a decrease in the activity of 11ß-HSD1 in association with elevations in growth hormone $(\mathrm{GH})$ and insulinlike growth factor (IGF)-I concentrations (21-24). In adult subjects with hypopituitarism, administration of GH in substitution doses leads to a significant, dose-independent, persistent decrease in the activity of $11 \beta$-HSD1, as evidenced by a decrease in the urinary cortisol to cortisone metabolite ratio (Fm/Em), which represents an index of the overall $11 \beta-H S D$ activity, with no concurrent alterations in the urinary free cortisol to free cortisone ratio (FF/FE), an index of $11 \beta-H S D 2$ activity $(22,24,25)$. In acromegalic patients, withdrawal from medical therapy results in a significant rise in GH and IGF-I concentrations and a concomitant decrease in the activity of $11 \beta-H S D 1$, while complete removal of the pituitary tumor by 
transphenoidal surgery results in a decrease in GH concentrations and a parallel increase in 11ß-HSD1 activity (23). In vitro studies, performed on cells stably transfected with either the human $11 \beta-H S D 1$ or $11 \beta-$ HSD2 complementary DNA and primary cultures of human omental adipose stromal cells expressing only the $11 \beta-H S D 1$ isozyme, indicate that IGF-I inhibits the activity of $11 \beta$-HSD1 in a dose-dependent manner. The effect of GH on the activity of $11 \beta$-HSD1 appears to be mediated by IGF-I. Neither GH nor IGF-I has any effect on the activity of type 2 isoform of the enzyme (23). By inhibiting the activity of $11 \beta$ HSD1, GH and IGF-I increase the metabolic clearance rate of cortisol (23).

The concept of decreased 11ß-HSD1 activity at puberty as a result of the rise in GH and IGF-I concentrations is supported by the fact that pubertal patients with classic $\mathrm{CAH}$ had significantly higher urinary excretion of cortisone metabolites [tetrahydrocortisone (THE)] than prepubertal and postpubertal patients (12) (Fig. 1A). A concomitant significant decrease in


Figure 1 (A) Urinary concentrations of cortisone metabolites and (B) urinary cortisol to cortisone metabolite ratio, which reflects the overall activity of $11 \beta$-hydroxysteroid dehydrogenase, in prepubertal, pubertal and postpubertal subjects with classic congenital adrenal hyperplasia. Asterisks indicate significant differences between groups. THE: tetrahydrocortisone; THF: tetrahydrocortisol. the urinary cortisol metabolite to cortisone metabolite $((\mathrm{THF}+$ allo-THF $) / \mathrm{THE})$ ratio, which represents an index of the overall activity of $11 \beta$-HSD1, was noted at puberty (12) (Fig. 1B). Furthermore, there was a significant positive correlation between the activity of $11 \beta$-HSD1 and the half-life of cortisol (Fig. 2), as well as between IGF-I concentrations and cortisol clearance corrected for body-mass index (BMI) (12) (Fig. 3). The decreased activity of $11 \beta$-HSD1 in patients with classic $\mathrm{CAH}$, who have minimal endogenous production of cortisol, will result in decreased conversion of cortisone to cortisol and hypocortisolism (Fig. 4). The latter will further activate the HPA axis and enhance adrenal hyperandrogenism.

In addition to GH and IGF-I, gonadal steroids may influence cortisol metabolism. In rats, a sexually dimorphic pattern in the activity of $11 \beta$-HSD 1 has been described, with females demonstrating significantly lower hepatic $11 \beta$-HSD1 activity and mRNA expression than males (26-29). In male rats, gonadectomy and estradiol treatment lead to a marked decrease in both $11 \beta$-HSD1 activity and mRNA expression, while gonadectomy and testosterone replacement have no such effect. On the other hand, in female rats, gonadectomy results in a marked increase in the activity of

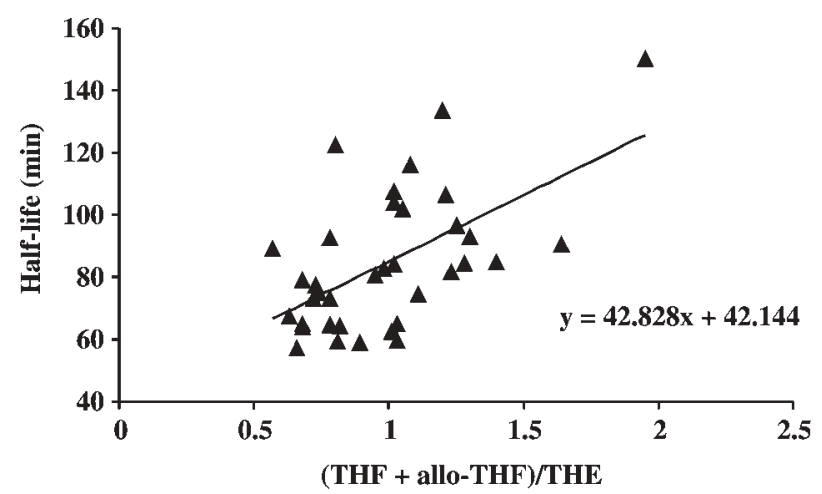

Figure 2 Linear correlation between 11ß-hydroxysteroid dehydrogenase activity and half-life of total cortisol. THE: tetrahydrocortisone; THF: tetrahydrocortisol.



Figure 3 Linear correlation between insulin-like growth factor (IGF)-I concentrations and total cortisol clearance (CL) corrected for body-mass index (BMI). 


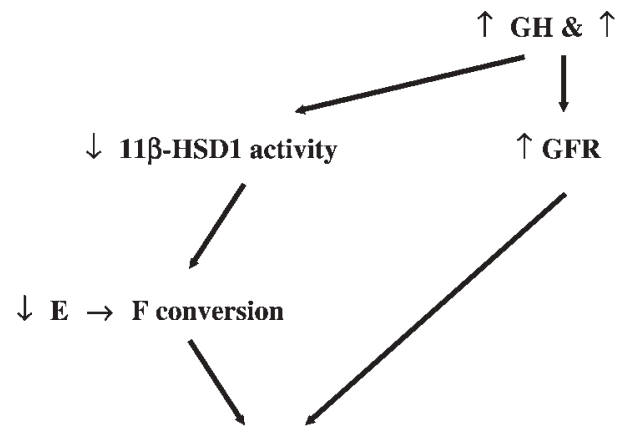

HYPOCORTISOLISM

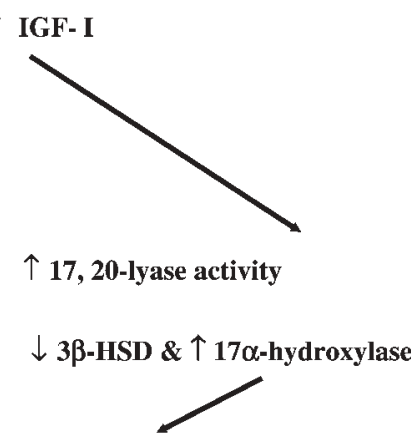

HYPERANDROGENISM

Figure 4 Schematic representation of the alterations in GH/IGF-I axis at puberty leading to suboptimal control of classic congenital adrenal hyperplasia despite optimal substitution therapy and adherence to medical treatment. E: cortisone; F: cortisol; GFR: glomerular

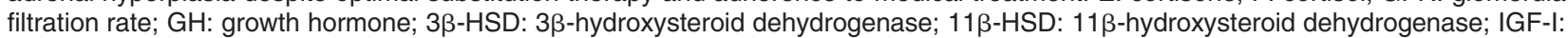
insulin-like growth factor $\mathrm{I}$.

$11 \beta-H S D 1$, which is reversed by estradiol but not testosterone replacement therapy (26). This sexually dimorphic pattern in the hepatic expression of $11 \beta$ HSD1 is pituitary-mediated and results from sex-specific differences in the pattern of GH secretion in the rat, with males demonstrating a pulsatile pattern and females displaying a rather continuous pattern of GH secretion (21, $27)$. Sexual dimorphism in the activity of $11 \beta$-HSD1 has been documented in healthy subjects (30) and patients with hypopituitarism receiving optimal replacement therapy (31), with females demonstrating decreased conversion of cortisone to cortisol compared with males. However, recent evidence suggests that the sexually dimorphic pattern in cortisol metabolism in humans is due to decreased A-ring reduction of cortisol in females compared with males rather than decreased reactivation of cortisone to cortisol by $11 \beta$-HSD1 $(32,33)$.

Besides their effects on the activity of $11 \beta-H S D 1, G H$ and IGF-I may contribute to the increased clearance of cortisol by increasing its renal excretion. Although cortisol metabolism is principally effected in the liver, a very small proportion of cortisol is excreted unchanged in the urine. Therefore, factors influencing renal clearance at puberty would have an effect, albeit small, on cortisol clearance. The renal clearance of a drug is the net result of three different processes: filtration, secretion and reabsorption. Renal clearance by filtration increases secondary to an increase in the glomerular filtration rate (GFR) (34). Both GH and IGF-I increase renal plasma flow and GFR (35) (Fig. 4). The action of $\mathrm{GH}$ is likely to be mediated by IGF-I rather than being direct. IGF-I increases renal GFR via a direct effect on the glomerular vasculature, a decrease in renal glomerular afferent and efferent arteriolar resistances, and an increase in the glomerular ultrafiltration coefficient $(36,37)$.

The rise in GH and IGF-I concentrations at puberty $(38,39)$ is associated with a marked fall in insulin sensitivity and a parallel elevation in serum insulin concentrations $(40,41)$. At the tissue level, insulin reduces
IGF-binding protein-1 (IGFBP-1) concentrations, further enhancing the effects of IGF-I on the activity of $11 \beta-H S D 1 \quad(42,43)$. Children with classic CAH have significantly higher serum insulin concentrations than those expected to arise as a result of the pubertal process itself, and a greater insulin resistance homeostasis model assessment (HOMA) index than their normal, BMI-matched counterparts (44). This is most likely the result of long-standing adrenomedullary hypofunction, given that catecholamines inhibit the secretion of insulin through $\beta$-adrenergic receptors (45). Obesity, intermittent hypercortisolism, and adrenal and/or ovarian hyperandrogenism in the not adequately controlled patients and/or females with polycystic ovarian syndrome (PCOS) may be additional factors that contribute to the elevated insulin concentrations and insulin resistance (46).

Further to increasing the metabolic clearance of cortisol, hormonal changes at puberty may enhance hyperandrogenism by influencing the activity of other enzymes participating in adrenal steroidogenesis. Human studies provide evidence for a decrease in the activity of $3 \beta-H S D$ and an increase in the activity of 17,20-lyase following administration of $\mathrm{GH}(47,48)$. In vitro studies performed on cultured human adrenal fasciculate-reticularis cells suggest that IGF-I and IGF-II enhance adrenal steroidogenesis by enhancing responsiveness to ACTH $(49-52)$. IGF-I and IGF-II enhance mostly androstenendione secretion in a dosedependent manner, with IGF-II being more potent than IGF-I in that respect $(51,52)$. The effect of IGF-I and IGF-II on adrenal steroidogenesis is associated with an increase in $17 \alpha$-hydroxylase and type II $3 \beta$ HSD activity and mRNA expression $(51,52)$ (Fig. 4).

Insulin stimulates primarily adrenal and, to a much lesser extent, ovarian steroidogenesis, and it constitutes an important component of the pathogenetic mechanism of hyperandrogenism $(49,50,53,54)$. In vitro studies performed on human adrenocortical cells have shown that physiologic concentrations of insulin 
increase $17 \alpha$-hydroxylase and $3 \beta$-HSD mRNA levels in the absence of cAMP or ACTH (49-51). Moreover, insulin decreases both 11ß-HSD1 activity and mRNA expression, and antagonizes the effect of glucocorticoids on the enzymatic activity of the 11ß-HSD1 (25). Human studies also support the concept of enhanced ACTH-mediated insulin-induced steroidogenesis (53). These effects of insulin would compound the effects of GH and IGF-I on 11 $\beta$-HSD1 activity, and would potentiate hypocortisolism and hyperandrogenism. The latter may be further amplified in hyperinsulinemic states, given that insulin suppresses the synthesis of sex hormone-binding globulin by the liver (55).

\section{Summary}

Alterations in the endocrine milieu at puberty are associated with alterations in cortisol pharmacokinetics, which lead to inadequate suppression of the HPA axis and suboptimal control of classic $\mathrm{CAH}$ despite optimal substitution therapy and adherence to medical treatment. The rise in GH and IGF-I concentrations may inhibit 11ß-HSD1 activity, resulting in decreased conversion of cortisone to cortisol and hypocortisolism. The increased GH/IGF-I concentrations in association with the elevated insulin concentrations at puberty may enhance adrenal and ovarian hyperandrogenism. Both hypocortisolism and hyperandrogenism will lead to increased secretion of ACTH, which will further amplify hypocortisolism by increasing the metabolic clearance rate of cortisol. Medical therapy of pubertal patients with classic 21-hydroxylase deficiency should be based on the understanding of the above pathophysiologic alterations, and should aim to provide appropriate glucocorticoid substitution, as well as to prevent and/or treat hyperandrogenism and insulin resistance.

\section{References}

1 Speiser PW \& White PC. Congenital adrenal hyperplasia. New England Journal of Medicine 2003349 776-788.

2 Merke DP, Bornstein SR, Avila NA \& Chrousos GP. NIH conference. Future directions in the study and management of congenital adrenal hyperplasia due to 21-hydroxylase deficiency. Annals of Internal Medicine 2002136 320-334.

3 Merke DP \& Cutler GB Jr. New ideas for medical treatment of congenital adrenal hyperplasia. Endocrinology and Metabolism Clinics of North America $200130121-135$.

4 White PC \& Speiser PW. Congenital adrenal hyperplasia due to 21-hydroxylase deficiency. Endocrine Reviews 200021 245-291.

5 Newfield RS \& New MI. 21-Hydroxylase deficiency. Annals of the New York Academy of Sciences $1997816219-229$.

6 Merke DP, Chrousos GP, Eisenhofer G, Weise M, Keil MF, Rogol AD, Van Wyk JJ \& Bornstein SR. Adrenomedullary dysplasia and hypofunction in patients with classic 21-hydroxylase deficiency. New England Journal of Medicine 2000343 1362-1368.

7 Charmandari E, Eisenhofer G, Mehlinger SL, Carlson A, Wesley R, Keil MF, Chrousos GP, New MI \& Merke DP. Adrenomedullary function may predict phenotype and genotype in classic 21hydroxylase deficiency. Journal of Clinical Endocrinology and Metabolism 200287 3031-3037.
8 Van Wyk JJ, Gunther DF, Ritzen EM, Wedell A, Cutler GB Jr, Migeon CJ \& New MI. The use of adrenalectomy as a treatment for congenital adrenal hyperplasia. Journal of Clinical Endocrinology and Metabolism 199681 3180-3190.

9 Tajima T, Ma XM, Bornstein SR \& Aguilera G. Prenatal dexamethasone treatment does not prevent alterations of the hypothalamic pituitary adrenal axis in steroid 21-hydroxylase deficient mice. Endocrinology $19991403354-3362$.

10 Janowski A. Naturally occurring adrenal steroids with salt losing properties: relationship to congenital adrenal hyperplasia. In Congenital Adrenal Hyperplasia, pp 99-112. Eds P Lee, L Plotnick, AA Kowarski \& C Migeon. Baltimore, MD: University Park Press, 1977.

11 Oelkers WK. Effects of estrogens and progestogens on the reninaldosterone system and blood pressure. Steroids $1996 \mathbf{6 1}$ 166-171.

12 Charmandari E, Hindmarsh PC, Johnston A \& Brook CG. Congenital adrenal hyperplasia due to 21-hydroxylase deficiency: alterations in cortisol pharmacokinetics at puberty. Journal of Clinical Endocrinology and Metabolism 200186 2701-2708.

13 Zisper RD, Speckart PF, Zia PK, Edmiston WA, Lau FYK \& Horton R. The effect of ACTH and cortisol on aldosterone and cortisol clearance and distribution in plasma and whole blood. Journal of Clinical Endocrinology and Metabolism 197643 1101-1109.

14 Gower DB. Steroid catabolism and urinary excretion. In Biochemistry of Steroid Hormones, pp 349-382. Ed. HLJ Makin. Oxford: Blackwell Science, 1984.

15 Iyer RB, Binstock JM, Scwartz IS, Gordon GG, Weinstein BI \& Southren AL. Human hepatic cortisol reductase activities: enzymatic properties and substrate specificities of cytosolic cortisol $\Delta^{4}-5 \beta$-reductase and dihydrocortisol- $3 \alpha$-oxidoreductase(s). Steroids $1990 \mathbf{5 5} 495-500$.

16 Stewart PM. 11 $\beta$-Hydroxysteroid dehydrogenase: implications for clinical medicine. Clinical Endocrinology (Oxford) $1996 \mathbf{4 4}$ 493-499.

17 Abel SM, Maggs JL, Back DJ \& Park BK. Cortisol metabolism by human liver in vitro. I. Metabolite identification and inter-individual variability. Journal of Steroid Biochemistry and Molecular Biology $199243713-719$.

18 Stewart PM \& Krozowski ZS. 11ß-Hydroxysteroid dehydrogenase. Vitamins and Hormones 199957 249-324.

19 Quinkler M \& Stewart PM. Hypertension and the cortisol-cortisone shuttle. Journal of Clinical Endocrinology and Metabolism $2003 \mathbf{8 8} 2384-2392$.

20 Tomlinson JW \& Stewart PM. Cortisol metabolism and the role of 11 beta-hydroxysteroid dehydrogenase. Best Practice and Research in Clinical Endocrinology and Metabolism 2001 15 61-78.

21 Low SC, Chapman KE, Edwards C, Wells T, Robinson IC \& Seckl JR. Sexual dimorphism of hepatic $11 \beta$-hydroxysteroid dehydrogenase in the rat: the role of growth hormone patterns. Journal of Endocrinology $1994143541-548$.

22 Gelding SV, Taylor NF, Wood PJ, Noonan K, Weaver JU, Wood DF \& Monson JP. The effect of growth hormone replacement therapy on cortisol-cortisone interconversion in hypopituitary adults: evidence for growth hormone modulation of extrarenal $11 \beta$ hydroxysteroid dehydrogenase activity. Clinical Endocrinology (Oxford) $1998 \mathbf{4 8} 153-162$.

23 Moore JS, Monson JP, Kaltsas G, Putignano P, Wood PJ, Sheppard MC, Besser GM, Taylor NF \& Stewart PM. Modulation of $11 \beta$-hydroxysteroid dehydrogenase isozymes by growth hormone and insulin-like growth factor: in vivo and in vitro studies. Journal of Clinical Endocrinology and Metabolism $1999 \mathbf{8 4}$ $4172-4177$.

24 Toogood AA, Taylor NF, Shalet SM \& Monson JP. Modulation of cortisol metabolism by low-dose growth hormone replacement in elderly hypopituitary patients. Journal of Clinical Endocrinology and Metabolism 200085 1727-1730.

25 Palermo M, Shackleton CHL, Mantero F \& Stewart PM. Urinary free cortisone and the assessment of 11 $\beta$-hydroxysteroid 
dehydrogenase activity in man. Clinical Endocrinology (Oxford) $199645605-611$.

26 Low SC, Assad SN, Rajan V, Chapman KE, Edwards CR \& Seckl JR. Regulation of $11 \beta$-hydroxysteroid dehydrogenase by sex steroids in vivo: further evidence for the existence of a second dehydrogenase in rat kidney. Journal of Endocrinology $199313927-35$.

27 Albiston AL, Smith RE \& Krozowski ZS. Sex- and tissue-specific regulation of $11 \beta$-hydroxysteroid dehydrogenase mRNA. Molecular and Cellular Endocrinology 1995109 183-188.

28 Jamieson P, Chapman KE, Edwards CRW \& Seckl JR. 11ßHydroxysteroid dehydrogenase is an exclusive $11 \beta$-reductase in primary cultures of rat hepatocytes: effect of physicochemical and hormonal manipulations. Endocrinology 1995136 $4754-4761$

29 Nwe KH, Hamid A, Morat PB \& Khalid BA. Differential regulation of the oxidative 11 $\beta$-hydroxysteroid dehydrogenase activity in testis and liver. Steroids 200065 40-45.

30 Raven PW \& Taylor NF. Sex differences in the human metabolism of cortisol. Endocrine Research 199622 751-755.

31 Weaver JU, Taylor NF, Monson JP, Wood PJ \& Kelly WF. Sexual dimorphism in 11ß-hydroxysteroid dehydrogenase activity and its relation to fat distribution and insulin sensitivity: a study in hypopituitary subjects. Clinical Endocrinology (Oxford) 199849 $13-20$.

32 Andrew R, Phillips DI \& Walker BR. Obesity and gender influence cortisol secretion and metabolism in man. Journal of Clinical Endocrinology and Metabolism 199883 1806-1809.

33 Finken MJ, Andrews RC, Andrew R \& Walker BR. Cortisol metabolism in healthy young adults: sexual dimorphism in activities of A-ring reductases, but not 11 beta-hydroxysteroid dehydrogenases. Journal of Clinical Endocrinology and Metabolism 199984 3316-3321.

34 Birkett DJ. Clearance of drugs by the kidneys. In Pharmacokinetics, ch 7, pp 55-65. Roseville: McGraw-Hill Australia, 1998.

35 Hammerman MR. The growth hormone-insulin-like growth factor axis in kidney revisited. Nephrology, Dialysis, Transplantation $1999141853-1860$.

36 Hirschberg R, Kopple J, Blantz R \& Tucker B. Effects of recombinant human insulin-like growth factor I on glomerular dynamics in the rat. Journal of Clinical Investigation 199183 1200-1206.

37 Krieg RL, Santos F \& Chan JCM. Growth hormone, insulin-like growth factor and the kidney. Kidney International $1995 \mathbf{4 8}$ 321-336.

38 Miller JD, Tannenbaum GS, Colle E \& Guyda HJ. Daytime pulsatile growth hormone secretion during childhood and adolescence. Journal of Clinical Endocrinology and Metabolism 198255 989-994.

39 Blum WF, Albertson-Wikland K, Rosberg S \& Ranke MB. Serum levels of insulin-like growth factor-I (IGF-I) and IGF binding protein-3 reflect spontaneous growth hormone secretion. Journal of Clinical Endocrinology and Metabolism 199376 1610-1616.

40 Amiel SA, Sherwin RS, Simonson DC, Iauritano AA \& Tamborlane WV. Impaired insulin action in puberty: a contributing factor to poor glycaemic control in adolescents with diabetes. New England Journal of Medicine 1986315 215-219.

41 Cutfield WS, Bergman AN, Menon RK \& Sperling MA. The modified minimal model application to measurement of insulin sensitivity in children. Journal of Clinical Endocrinology and Metabolism $1990701644-1650$.

42 Conover CA, Butler PC, Wang M, Rizza RA \& Lee PDK. Lack of growth hormone effect on insulin-associated suppression of insulin-like growth factor binding protein-I in humans. Diabetes 1990 $391251-1256$.

43 Travers SH, Labarta JI, Gargosky SE, Rosenfeld RG, Jeffers BW \& Eckel RH. Insulin-like growth factor binding protein-I levels are strongly associated with insulin sensitivity and obesity in early pubertal children. Journal of Clinical Endocrinology and Metabolism 199883 1935-1939.

44 Charmandari E, Weise M, Bornstein SR, Eisenhofer G, Keil MF, Chrousos GP \& Merke DP. Children with classic congenital adrenal hyperplasia have elevated serum leptin concentrations and insulin resistance: potential clinical implications. Journal of Clinical Endocrinology and Metabolism $2002872114-2120$.

45 Nonogaki K. New insights into sympathetic regulation of glucose and fat metabolism. Diabetologia 200043 533-549.

46 Dunaif A. Insulin resistance and the polycystic ovary syndrome: mechanism and implications for pathogenesis. Endocrine Reviews $199718774-800$

47 Merola B, Rossi E, Colao A, Cataldi M, Longobardi S, Schettini G \& Lombardi G. Effect of a short-term treatment with recombinant growth hormone $(\mathrm{GH})$ on adrenal responsiveness to corticotrophin stimulation in children affected by isolated GH deficiency. Journal of Clinical Endocrinology and Metabolism $1992 \mathbf{7 4}$ $1210-1214$.

48 Balducci R, Toscano V, Larizza D, Mangiantini A, Galasso C, Municchi G, Di Rito A, Picone S \& Boscherini B. Effects of longterm growth hormone therapy on adrenal steroidogenesis in Turner syndrome. Hormone Research 199849 210-215.

49 L'Allemand D, Penhoat A, Lebrethon MC, Ardevol R, Baehr V, Oelkers W \& Saez JM. Insulin-like growth factors enhance steroidogenic enzyme and corticotropin receptor messenger ribonucleic acid levels and corticotropin steroidogenic responsiveness in cultured human adrenocortical cells. Journal of Clinical Endocrinology and Metabolism $1996 \mathbf{8 1} 3892-3897$.

50 Kristiansen SB, Endoh A, Casson PR, Buster JE \& Hornsby PJ. Induction of steroidogenic enzyme genes by insulin and IGF-I in cultured adult human adrenocortical cells. Steroids $199762258-265$.

51 Mesiano S, Katz SL, Lee JY \& Jaffe RB. Insulin-like growth factors augment steroid production and expression of steroidogenic enzymes in human fetal adrenal cortical cells: implications for adrenal androgen regulation. Journal of Clinical Endocrinology and Metabolism 199782 1390-1396.

52 Fottner C, Engelhardt D \& Weber MM. Regulation of steroidogenesis by insulin-like growth factors (IGFs) in adult human adrenocortical cells: IGF-I and, more potently, IGF-II preferentially enhance androgen biosynthesis through interaction with the IGF-I receptor and IGF-binding proteins. Journal of Endocrinology 1998158 409-417.

53 Moghetti P, Castello R, Negri C, Tosi F, Spiazzi GG, Brun E, Balducci R, Toscano V \& Muggeo M. Insulin infusion amplifies 17 alpha-hydroxycorticosteroid intermediates response to adrenocorticotropin in hyperandrogenic women: apparent relative impairment of 17,20-lyase activity. Journal of Clinical Endocrinology and Metabolism $1996 \mathbf{8 1} 881-886$.

54 Nestler JE, Jakubowicz DJ, de Vargas AF, Brik C, Quintero N \& Medina F. Insulin stimulates testosterone biosynthesis by human thecal cells from women with polycystic ovary syndrome by activating its own receptor and using inositolglycan mediators as the signal transduction system. Journal of Clinical Endocrinology and Metabolism $1998 \mathbf{8 3} 2001-2005$.

55 Singh A, Hamilton-Fairley D, Koistinen R, Seppala M, James VH, Franks S \& Reed MJ. Effect of insulin-like growth factor-type I (IGF-I) and insulin on the secretion of sex hormone binding globulin and IGF-I binding protein (IBP-I) by human hepatoma cells. Journal of Endocrinology $1990 \mathbf{1 2 4}$ R1-R3.

Received 1 June 2004

Accepted 5 August 2004 